\title{
Effects of vertically propagating mountain waves during a strong wind event over the Ross Ice Shelf, Antarctica
}

\author{
Sheeba Nettukandy Chenoli ${ }^{1,2,3, *}$, John Turner ${ }^{4}$ and Azizan Abu Samah ${ }^{1,2,3}$ \\ ${ }^{1}$ Department of Geography, Faculty of Arts and Social Sciences, University of Malaya, Kuala Lumpur, Malaysia \\ ${ }^{2}$ National Antarctic Research Centre, Institute of Graduate Studies, University of Malaya, Kuala Lumpur, Malaysia \\ ${ }^{3}$ Institute of Ocean and Earth Sciences, University of Malaya, Kuala Lumpur, Malaysia \\ ${ }^{4}$ British Antarctic Survey, Cambridge, United Kingdom
}

Weather forecasting in the Antarctic presents many challenges, with strong wind events (SWEs) often disrupting air and field operations. Here, we study the mechanisms responsible for a SWE (maximum wind speed $22 \mathrm{~ms}^{-1}$ ) that occurred at the McMurdo/Scott Base region on the Ross Ice Shelf (Antarctica) over 12-13 October 2003. The study is based on in situ observations, satellite imagery and output from the Antarctic mesoscale prediction system (AMPS) model. The event occurred during the passage of a complex low pressure system that increased the pressure gradient between the northwest Ross Ice Shelf and the continental high, initiating a strong southerly flow. AMPS simulations as well as upper air sounding profiles from McMurdo station showed the involvement of large amplitude vertically propagating mountain waves over the area. The amplification of mountain waves by the self-induced critical level reflected all the energy back towards the surface to generate high downslope winds.

Keywords: Katabatic wind, mesoscale model, mountain wave, strong wind events.

\section{Introduction}

THE wind field over Antarctica has been studied for almost a century and the dynamics of the airflow over the continent are well understood. From the recent literature, it is evident that the Antarctic strong wind events (SWEs) are forced by diabatic cooling of surface air and the pressure gradient force generated by the synoptic influence of cyclones in the coastal margin and due to topography $^{1-3}$.

The present study aims to examine the occurrence, nature and dynamical environments of SWE over the northwest Ross Ice Shelf, Antarctica and the mechanisms responsible for its development. We define SWEs as events with a wind speed greater than Beaufort scale 6

\footnotetext{
*For correspondence. (e-mail: sheeba@um.edu.my)
}

and above, which is more than 22 knots or $11.3 \mathrm{~ms}^{-1}$ for a duration $>6 \mathrm{~h}$ (refs 3,4$)$.

\section{Data and methods}

A major part of this study is based on observational analysis from AWS and mesoscale output. The data consists of surface observations from automatic weather stations (AWS), surface and upper-air radiosonde data from McMurdo Station, and moderate resolution imaging spectroradiometer (MODIS) satellite imagery. The European Centre for Medium-Range Weather Forecasts (ECMWF), ERA interim reanalysis ${ }^{5}$ data were also used to supplement the in situ data to obtain a detailed insight into the synoptic background. We utilized the data from the Malaysian Antarctic Research Program (MARP) AWS1 $\left(77.908^{\circ} \mathrm{S}, 167.058^{\circ} \mathrm{E}\right)$ and AWS2 $\left(77.898^{\circ} \mathrm{S}, 167.098^{\circ} \mathrm{E}\right)$ (hereafter referred to as WF-AWS1 and WF-AWS2 respectively). Radiosonde data from McMurdo were used to assess the upper air meteorological conditions during the SWEs (ftp://amrc.ssec.wisc.edu/pub/mcmurdo/radiosonde/).

Numerical weather model output from the AMPS archive was also used to study certain salient features of SWEs at McMurdo/Scott Base region. The AMPS Polar MM5 covers five polar stereographic domains. Domains 2 (30 km resolution), 3 (10 km resolution) and $5(3.3 \mathrm{~km}$ resolution) are used in this analysis.

\section{An overview of the development of a SWE and} the synoptic situation

Our selected SWE was caused by the passage of a subsynoptic scale low pressure system that formed on the Rose Ice Shelf from a pre-existing trough extending from another synoptic low pressure over the Ross Sea. When the low pressure system approached the station (Figure 1), it strengthened the pressure gradient between the northwestern ice shelf and the continental high.

The track of the low pressure system (L1) that gave rise to the SWE is shown in Figure 2. It was determined 


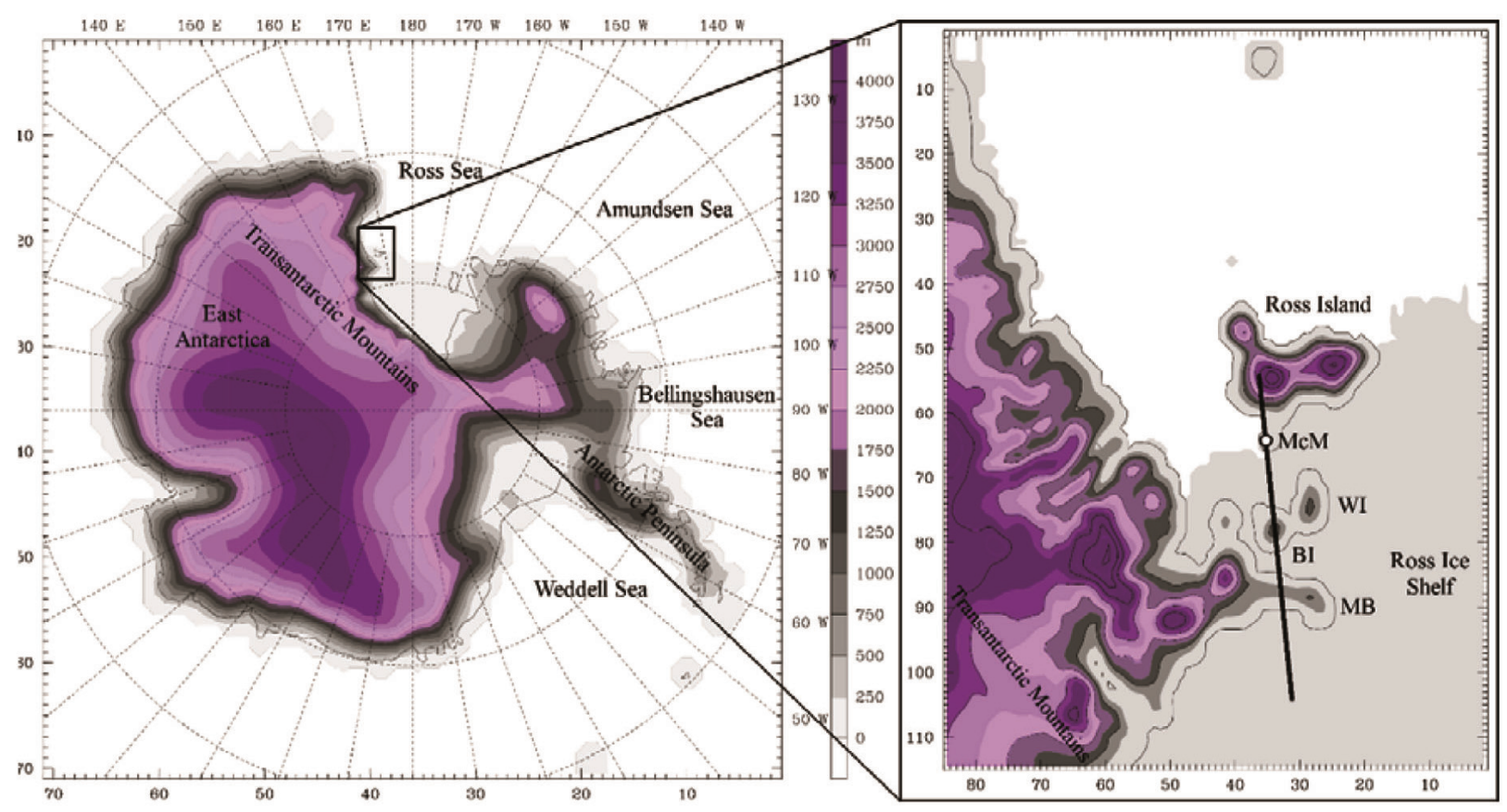

Figure 1. Map of the study area with AMPS terrain contours (shaded, $250 \mathrm{~m}$ interval). McM, WI, BI, MB represent McMurdo, White Island, Black Island and Minna Bluff respectively.

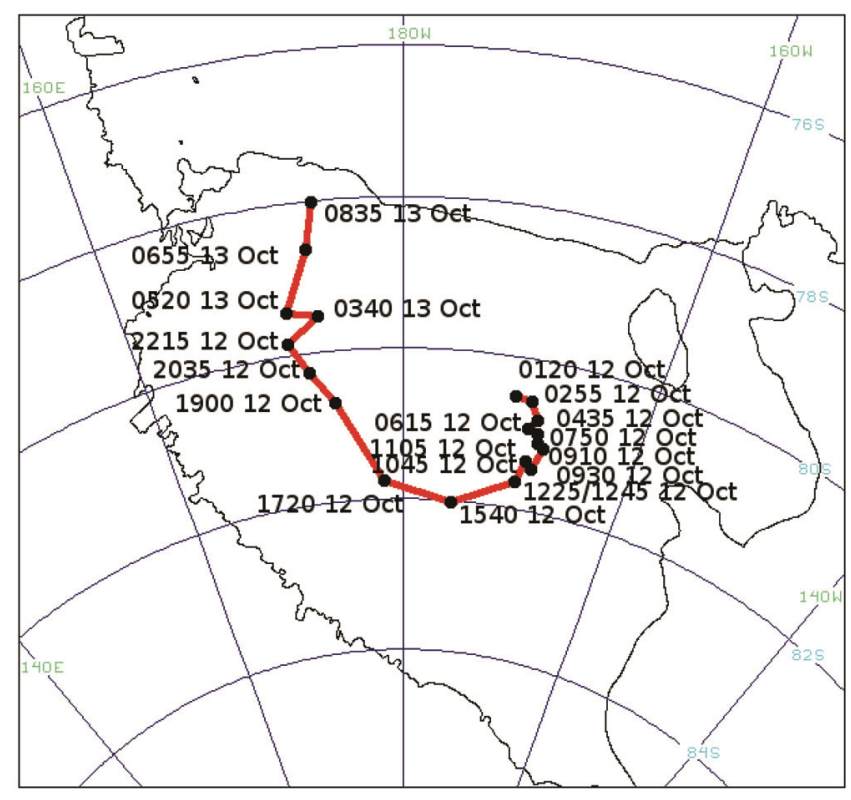

Figure 2. Track of low pressure system L1.

from MODIS satellite images taken from 0120 UTC 12 October to 0835 UTC 13 October 2003. L1 developed on the Rose Ice Shelf and was first detected through satellite imaging as an organized cloud mass at 0120 UTC 12 October. ERA Interim reanalysis at 1200 UTC 12 October confirmed that the L1 developed from a preexisting trough of low pressure over the Rose Ice Shelf. This pre-existing trough extended from a relatively large scale low pressure system (L2) positioned over the Ross
Sea (Figure $3 a$ and $b$ ). Initially, L1 moved slowly towards the southeast for a short while and then moved towards northwest. It took $31 \mathrm{~h}$ to reach the eastern side of the Ross Island at 0835 UTC 13 October.

L2 was more displaced towards the east in the satellite imagery as compared to the reanalysis MSLP field. Satellite images (not shown) also showed intensifying L1 moved in a northwest direction towards the station until 1900 UTC 12 October 2003. On the western side of the Ross Ice Shelf, the satellite image shows dark signatures of katabatic winds in the infrared channel. There were indications of katabatic outflow from Marie Byrd Land (see arrow in Figure $3 a$ ) being drawn into the circulation of L1. The MSLP field from the reanalysis at 1800 UTC 12 October 2003 (Figure $4 b$ ) showed that the movement of L1 towards the station area and intensification of the continental high strengthened the pressure gradient over the Ross Ice Shelf. L1 dissipated and was not visible in the satellite images from 0835 UTC 13 October onwards. At this point, the pressure gradient over the station area remained the same due to approaching L2.

In situ observations from the Williams Field AWS showed a rapid increase in wind speed from $1.6 \mathrm{~ms}^{-1}$ at 1940 UTC to $11 \mathrm{~ms}^{-1}$ at 1955 UTC (Figure 5) on 12 October 2003. The wind backed from $270^{\circ}$ to $180^{\circ}$ with increase in wind speed. Maximum wind speed was reached during the event $\left(22 \mathrm{~ms}^{-1}\right)$ which continued for $11 \mathrm{~h}$. The minimum pressure noted during the event was $965 \mathrm{hPa}$ at $0530 \mathrm{UTC} 13$ October 2003. The wind direction backed towards north when the speed dropped below $10 \mathrm{~ms}^{-1}$ at 0800 UTC 13 October. Temperature and 

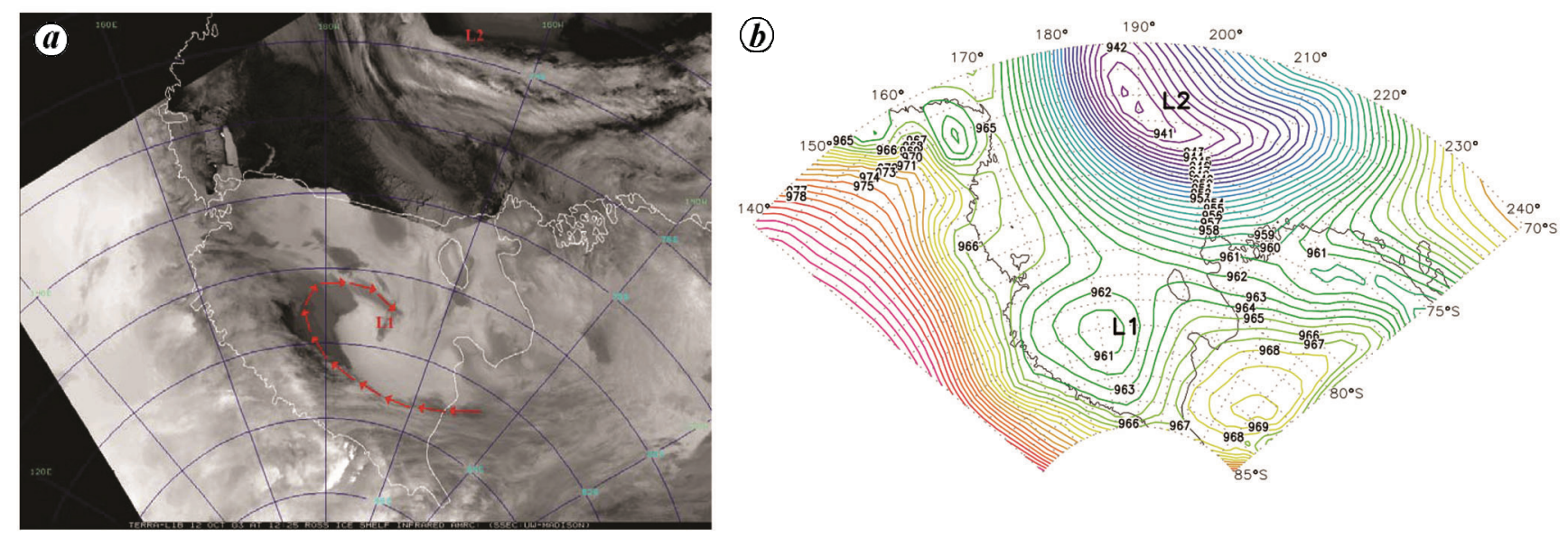

Figure 3. (a) MODIS image at 1225 UTC and (b) MSLP from ERA at 1200 UTC 12 October 2003.
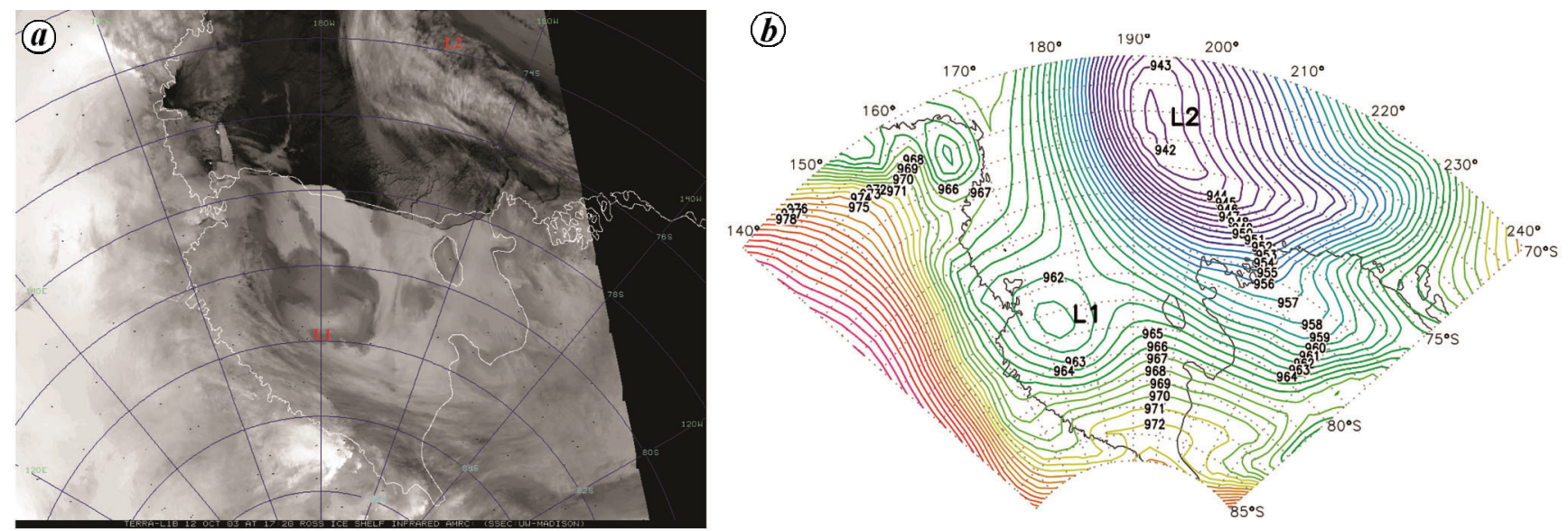

Figure 4. (a) MODIS imagery at 1720 UTC and (b) MSLP from ERA at 1800 UTC 12 October 2003.

humidity increased by $5^{\circ} \mathrm{C}$ and $5 \%$ respectively, during the event.

\section{Effects of vertically propagating mountain waves}

Major topographical features on the northwest Ross Ice Shelf are the complex terrain of Minna Bluff, Black and White Island and Ross Island (Figure 1). When southerly strong wind flows over these topographical features, depending on the wind speed, this can result in the formation of mountain wave as it propagates downstream from high terrain of height varying from 1500 to $2500 \mathrm{~m}$. Amplification of the waves to downslope windstorms on the downstream side of the topographical barrier depends on a range of conditions that allow trapping of wave energy. Many theories were proposed for the account of the generation and intensification of mountain waves into wind storm events ${ }^{6,7}$. The AMPS vertical cross-section of potential temperature distribution during the SWE suggests the patterns of wave structure similar to the poten- tial temperature pattern during a downslope wind storm in Colorado ${ }^{6,7}$. In order to prevent vertical propagation of energy, the stable lower layer of the atmospheric flow must be bounded by a region above, which effectively reflects the vertically propagating waves, thus creating a wave duct where the waves propagates horizontally without great loss of energy. The possible wave amplification is determined by the superposition of downward reflecting and upward reflecting waves. This scenario requires a critical layer to restrict mountain wave activity. The critical layer can either be an inversion layer, where there is a large variation of thermal stability or a layer that is more stable compared to the layer below.

Figure 7 shows the upper air observations from McMurdo station at 1200 UTC 12 October 2003. It has features similar to the three-layer atmospheric model employed in the studies ${ }^{5}$ of downslope winds at Boulder. Figure 8 shows a lower layer L1 extending from 960 to $620 \mathrm{hPa}$ and another comparatively more stable layer (L2) above $580 \mathrm{hPa}$ which is separated by an isothermal layer. This isothermal layer can be considered the critical 

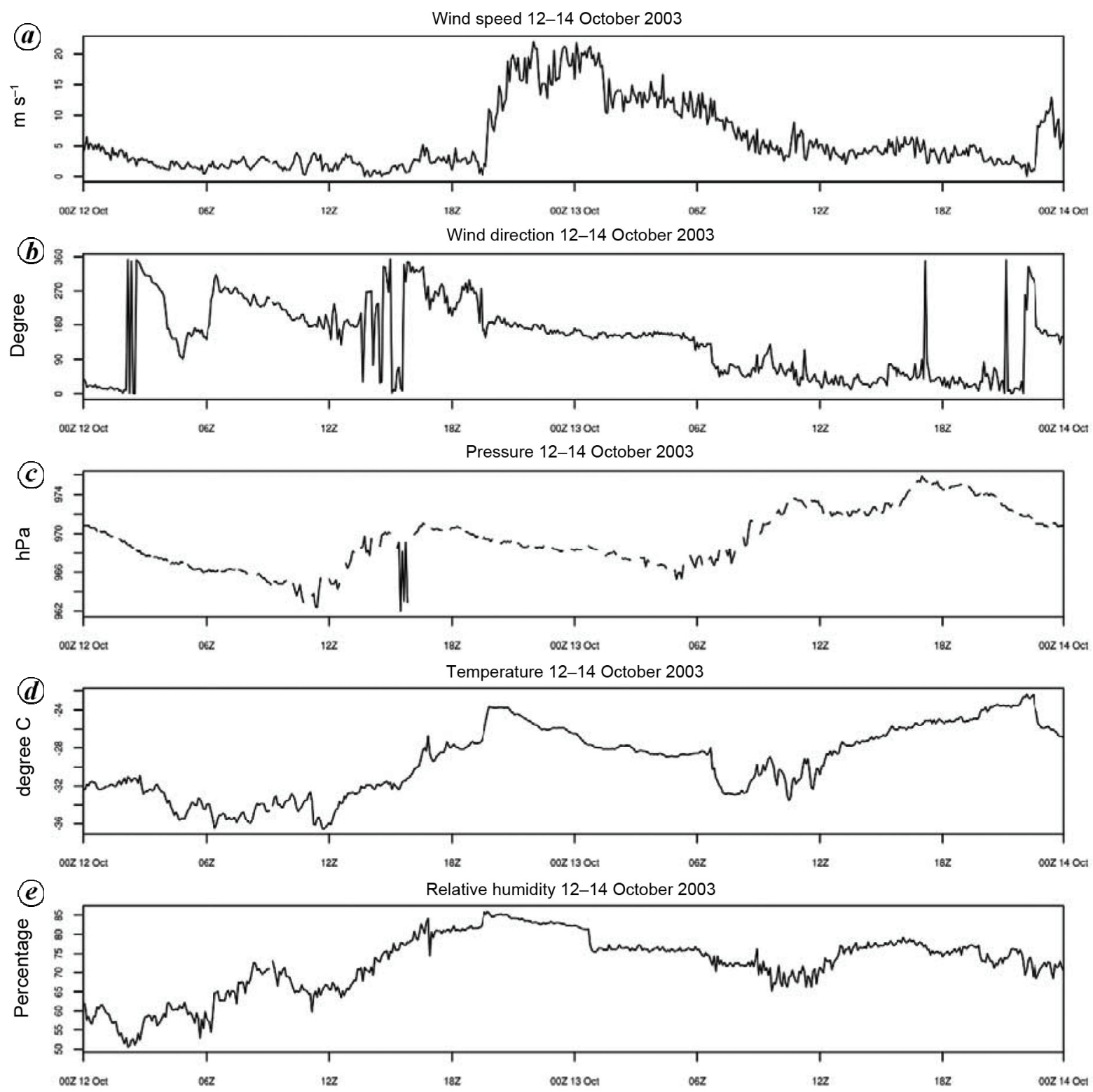

Figure 5. Time series of meteorological parameters: $(\boldsymbol{a})$ wind speed; $(\boldsymbol{b})$ wind direction; (c) MSLP; and (d) relative humidity from WF-AWS1.

layer where stable air met less stable air above it and stopped the mountain waves from propagating vertically. Notice the veering of the wind direction from south easterlies to northwesterly and a decrease in wind speed above this level. Many earlier studies showed that decreasing static stability with height is a favourable condition for wave amplification, with a stable layer near the mountain top level. It is possible for large-amplitude vertically propagating mountain waves to undergo partial reflection at stable interfaces. Maximum amplification of the surface velocity was shown ${ }^{5}$ in a three-layer system when each of the two layers have one fourth the thickness of the vertical wavelength in the respective layer. This will result in the resonance of waves and their amplification.
The average vertical wavelength of the wave motion is

$$
\lambda_{i}=\frac{2 \pi}{N_{i}} \frac{U_{i+} U_{i+1}}{2},
$$

where $U$ and $N$ are wind speed and the Brunt-Väisälä frequency respectively, for layer $i$. Using values calculated from the radiosonde ascents

$$
\begin{aligned}
& N_{1}=1.25 \times 10^{-2} U_{1}=5.7 \mathrm{~ms}^{-1} \\
& N_{2}=1.78 \times 10^{-2} U_{2}=8.4 \mathrm{~ms}^{-1}
\end{aligned}
$$

Utilizing the values from eqs (2) and (3), the computed layer for the optimal response is $3539 \mathrm{~m}$. Therefore, the 

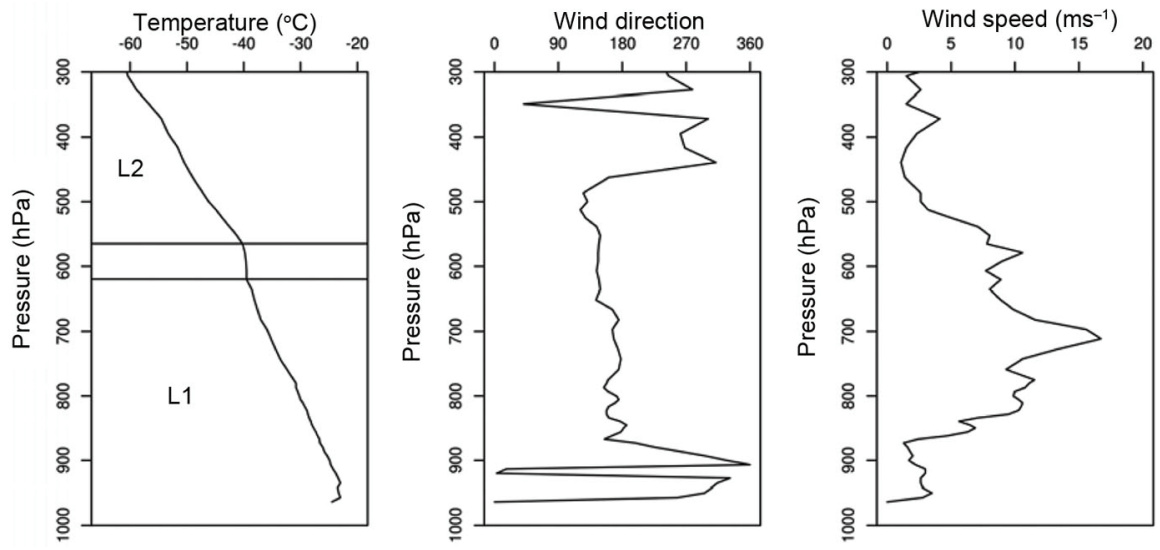

Figure 6. Upper air sounding from McMurdo station at 1200 UTC 12 October 2003.

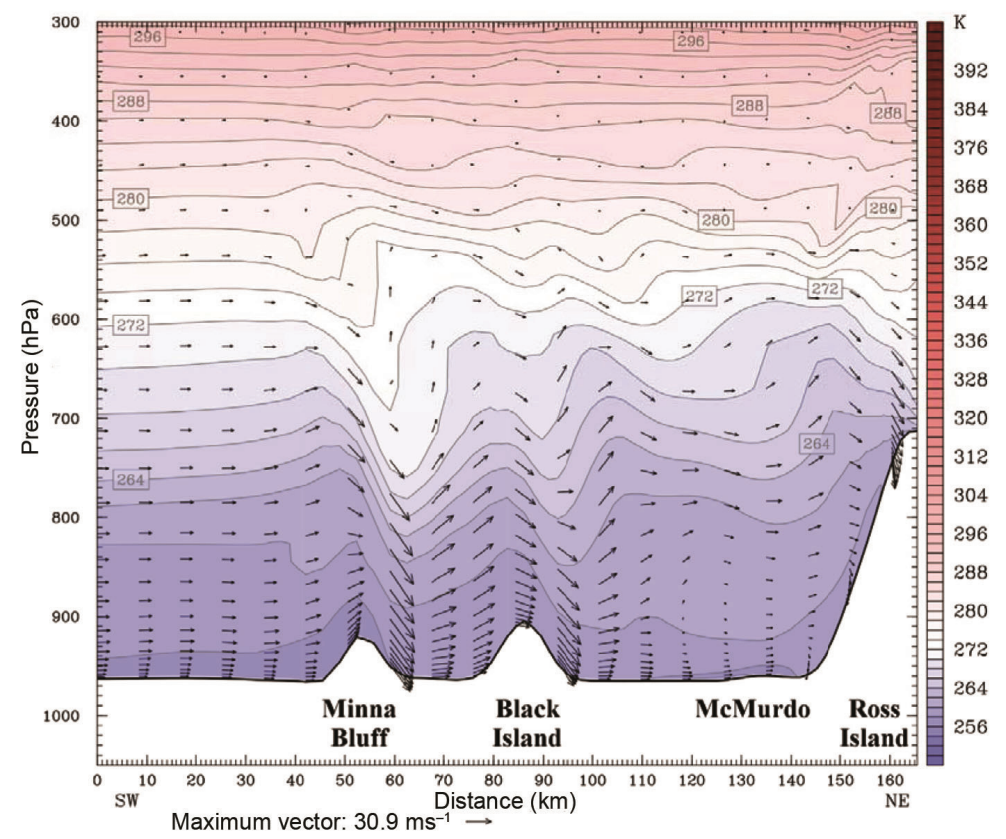

Figure 7. Cross-section potential temperature (contoured, interval $2 \mathrm{~K}$ ) (for the location of the transect, see Figure 1) and resultant of meridional and vertical component wind vectors $\left(\mathrm{ms}^{-1}\right)$ at 2100 UTC 12 October 2003 from $3.3 \mathrm{~km}$ AMPS domain.

critical layer can be at $570 \mathrm{hPa}$. From examining the upper air temperature, the less stable layer contains the critical layer at $570 \mathrm{hPa}$. This can enhance reflectivity (Figure 6). However, the case of mountain waves over McMurdo can be more complex as the area has complex and varying topography making it hard to solve with a simple mathematical tools.

To study this further, the operational run of AMPS for the duration of this period was examined since upper air data were only available for McMurdo. Figure 7 shows the vertical cross-section of potential temperature and resultant of meridional and vertical component vectors from the $3.3 \mathrm{~km}$ grid at 2100 UTC 12 October 2003, when the surface wind speed at the AWS was $20 \mathrm{~ms}^{-1}$. The potential temperature and wind vector show the pres- ence of the distinctive wave flow pattern in the lee of the mountain barrier similar to the downslope wind storm at Boulder. From the surface to $700 \mathrm{hPa}$ away from the ranges, widely spaced isentropes were observed, indicating weaker static stability. Above and close to higher topography a stable layer with closely packed isentropes was observed. The stability interface is located just above the $820 \mathrm{hPa}$ upstream of Minna Bluff and another at the height of $600 \mathrm{hPa}$. A strong potential temperature gradient present over the lee side of high topography with high wind speeds below $820 \mathrm{hPa}$.

Figure 8 shows the cross-section of resultant of meridional and vertical component wind speed (shaded colours area (interval of $2 \mathrm{~ms}^{-1}$ )) and potential temperature (black contours) for the same horizontal position as in Figure 7 


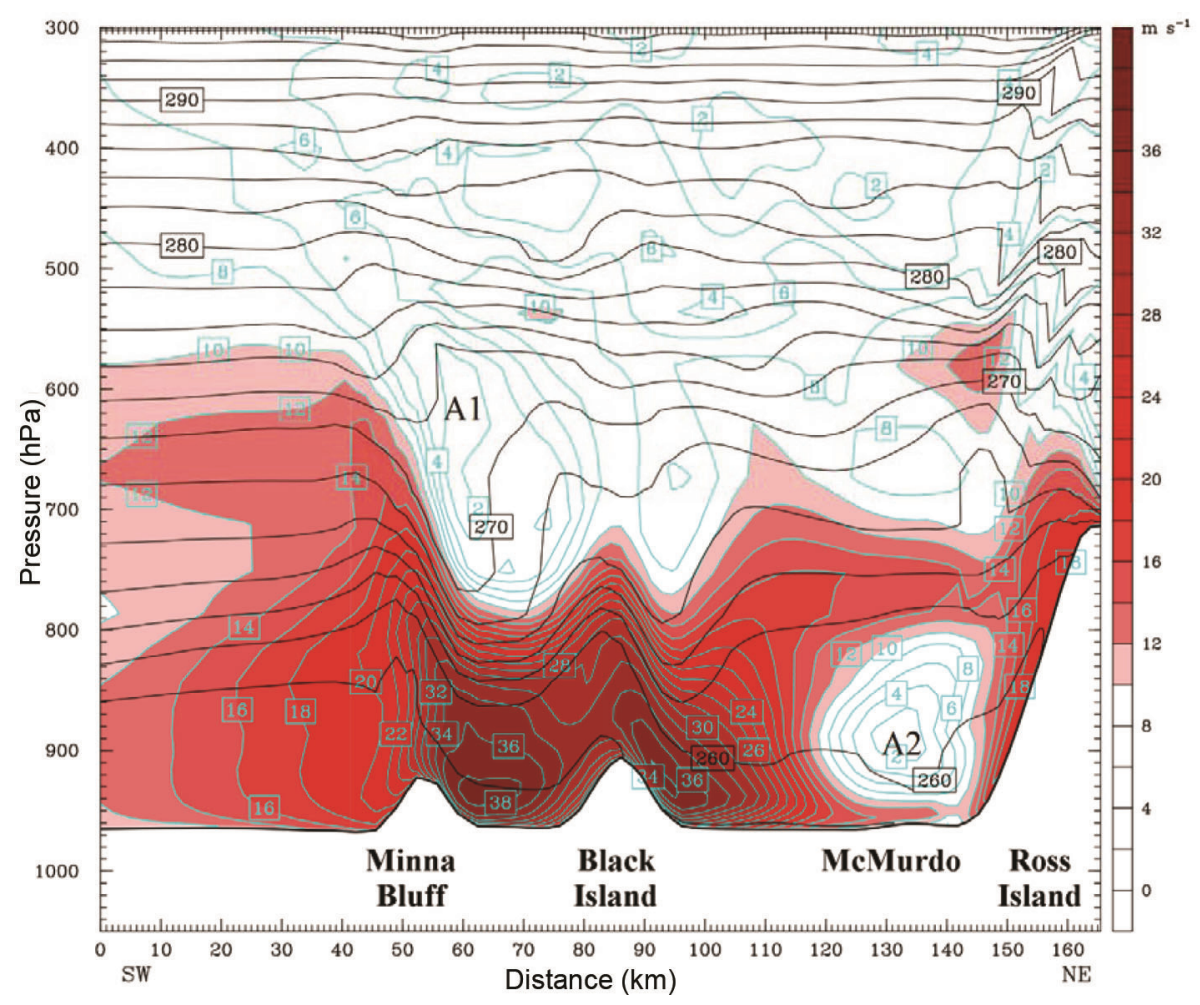

Figure 8. Vertical cross-section (for the location of the transect, see Figure 1) of resultant of horizontal and vertical wind speed and potential temperature at 0000 UTC 13 October 2003.

from AMPS $3.3 \mathrm{~km}$ grid at 0000 UTC 13 October. Two maxima in horizontal wind are noted on the lee side of Minna Bluff and Black Island (Figure 8). Two low wind speed areas can be observed between $700 \mathrm{hPa}$ and $500 \mathrm{hPa}$ altitude (A1) and another area south (A2) of McMurdo at around $900 \mathrm{hPa}$ near Ross Island. The low wind speed area A1 is characterized by steeply rising isentropes which signify upward motion. This can be due to the hydraulic jump caused by the transition of flow from critical to subcritical at the layer. The McMurdo wind speed increases with height till $950 \mathrm{hPa}$.

\section{Summary and conclusion}

The SWE on 12-13 October 2003 was associated with the passage of a sub-synoptic low pressure system that formed on the Ross Ice Shelf from a pre-existing trough extending from another synoptic low pressure over Ross Sea. Major features of this event consisted of a rapid increase in wind speed from 1.6 to $11 \mathrm{~ms}^{-1}$ within a few minutes during the onset of SWE.

The role of low pressure systems is to mainly initiate the enhancement of southerly flow by strengthening the pressure gradient over the northwest Ross Ice Shelf. When the southerly winds are greater than $15 \mathrm{~ms}^{-1}$, it is possible to develop mountain wave along the lee slopes of Minna Bluff, Black Island and White Island. Downslope winds develop at the lee sides of the barriers when the mountain waves are amplified under favourable conditions.

1. Steinhoff, D. F., Bromwich, D. H., Lambertson, M., Knuth, S. L. and Lazzara, M. A., A dynamical investigation of the May 2004 McMurdo Antarctica severe wind event using AMPS. Mon. Wea. Rev., 2008, 136, 7-26; doi:10.1175/2007MWR 1999.1.

2. Turner, J., Chenoli, S. N., Abu Samah, A., Marshall, G., Phillips, T. and Orr, A., Strong wind events in the Antarctic. J. Geophys. Res., 2009, 114, D18103; doi:10.1029/2008JD011642.

3. Chenoli, S. N., Turner, J. and Samah, A. A., A strong wind event on the Ross Ice Shelf, Antarctica: a case study of scale interactions. Mon. Wea. Rev., 2015, 143, 4163-4180.

4. Chenoli, S. N., Turner, J. and Samah, A. A., A climatology of strong wind events at McMurdo Station, Antarctica. Int. J. Climatol., 2012, 33, 2667-2681; doi:https://doi.org/10.1002/joc.3617

5. Dee, D. P. et al., The ERA-interim reanalysis: configuration and performance of the data assimilation system. QJR Meteorol. Soc., 2011, 137, 553-597.

6. Klemp, J. B. and Lilly, D. R., The dynamics of wave-induced downslope winds. J. Atmos. Sci., 1975, 32, 320-339.

7. Durran, D. R., Mountain waves, mesoscale meteorology and forecasting. Am. Meteorol. Soc., 1986, 472-492.

ACKNOWLEDGEMENTS. This study was supported by the Ministry of Science Technology and Innovation (MOSTI) Grant FP1213E037, University of Malaya Research Grant (RP002B-13SUS and RP026D18SUS) and Malaysian Antarctic Research Program, Academy of Sciences, Malaysia (ASM). The authors appreciate the support of the Automatic Weather Station Program for the data and information (Dr Matthew Lazzara, AMRC staff) NSF grants number ANT-0636873 and ANT-0838834.

doi: $10.18520 / \mathrm{cs} / \mathrm{v} 115 / \mathrm{i} 9 / 1684-1689$ 